\title{
Lack of immune deficiency in sarcoidosis: compartmentalisation of the immune response
}

\author{
B N HUDSPITH, K C FLINT, D GERAINT-JAMES, J BROSTOFF, N MCI JOHNSON \\ From the Department of Immunology and the Medical Unit, Middlesex Hospital Medical School, and the Royal \\ Northern Hospital, London
}

ABSTRACT The original findings of peripheral anergy in sarcoidosis led to the conclusion that sarcoidosis was a disease associated with immune deficiency, but patients with sarcoidosis do not appear to suffer from repeated infections suggestive of immune suppression. With the technique of bronchoalveolar lavage it is now possible to examine the local immune response within the lung, the most commonly affected organ in sarcoidosis. In this study three different indices of cell mediated immunity (lymphocyte transformation, interleukin-2 production, and interleukin-1 production) have been examined by comparison of cells recovered by lavage with those collected from peripheral blood. It was found that in vitro anergy was confined to peripheral blood cells, where all three markers of the immune response used in this study was impaired in the 12 patients with sarcoidosis group when compared with results in the 12 controls, with the most depressed responses seen in those patients classified as having active disease (lymphocyte proliferation 45\% (SD 17\%); interleukin-2 production $44 \%$ (13\%), and interleukin-1 production $31 \%$ (10\%) of control levels). By contrast, $\mathrm{T}$ lymphocytes recovered from the lungs of patients with sarcoidosis showed a greater response than did those from controls in terms of lymphocyte transformation and interleukin-2 production; these differences were greatest in those with active disease (lymphocyte proliferation $209 \%(27 \%)$ and interleukin-2 production $202 \%$ (19\%) of control levels). Interleukin-1 production by cells of the monocyte lineage recovered from the lung gave similar results to those of the control and sarcoid groups. It is concluded that the anergy seen in the peripheral blood compartment possibly reflects redistribution of $\mathrm{T}$ lymphocytes rather than a generalised immune deficiency.

\section{Introduction}

Sarcoidosis is a multisystem disease of unknown cause characterised by non-caseating granuloma formation. It is associated with anergic responses to skin tests and depressed peripheral $\mathrm{T}$ lymphocyte responses in vitro. ${ }^{12}$

We have previously shown that this peripheral anergy is partly due to decreased production of the monokine interleukin-1 (IL-1) by monocytes. ${ }^{3}$ We and other authors have also shown that peripheral blood monocytes contribute to the supressed lymphocyte responses by releasing increased amounts of prostaglandins. ${ }^{45}$

Despite the impaired peripheral cell mediated immune responses in patients with sarcoidosis these

Address for reprint requests: Dr N McI Johnson, Medical Unit, Middlesex Hospital, London WIN 8AA.

Accepted 28 October 1986 patients do not appear to develop the clinical sequelae of significant immune suppression. They are therefore presumably capable of mounting effective local humoral and cellular immune responses. The localisation of these effective responses to the affected organs could be responsible for the peripheral anergy associated with this disease. ${ }^{67}$ The development of the technique of bronchoalveolar lavage has enabled studies of pulmonary immune effector cells to be undertaken. By means of this technique increased numbers of $T$ lymphocytes have been found in the lavage fluid of patients with active sarcoidosis. ${ }^{8}$ This increase has been shown to be due to greater numbers of activated $\mathrm{T}$ helper cells ${ }^{7}$ and Pinkston has suggested that this may be due to the spontaneous proliferation of $\mathrm{T}$ cells that are releasing lymphokines, particularly interleukin-2.9 Work from the same department has also indicated that lavage macrophages obtained from patients with sarcoidosis are activated, thus resulting in increased local interleukin1 production within the lung. ${ }^{10}$ The mechanism by 
which these cells have become activated remains unknown.

In an attempt to resolve the paradox of peripheral anergy coexisting with local immune competence we have compared lymphocyte transformation and interleukin-1 and interleukin-2 production from cells recovered from bronchoalveolar lavage and blood in patients with pulmonary sarcoidosis.

\section{Methods}

\section{PATIENTS}

We studied 12 subjects who were recruited consecutively from a sarcoidosis assessment clinic. All underwent routine clinical examination, lung function testing, chest radiography, bronchoalveolar lavage, and gallium scintigraphy. Patients were divided into two groups. ${ }^{11}$ The first group consisted of seven patients (mean age 41, range 35-50 years; four men; one negro, three Asians and three Europeans). A positive gallium scan was found in six patients in this group. Of the seven patients, five had noted increasing shortness of breath and a deterioration in vital capacity and transfer factor had been recorded. Chest radiography showed stage I changes in three, stage II changes in three, and stage III changes in one. All seven had over $28 \%$ lymphocytes in their lavage fluid. The second group of five subjects (mean age 39, range 22-63 years, two men; two Negroes, one Asian, and two Europeans). All five had less than $28 \%$ lymphocytes in BAL their lavage fluid and also negative gallium scans. No patient in this group complained of worsening symptoms and their spirometric values had not changed since the previous visit. Chest radiographs showed stage I changes in two, stage II in one, and stage III changes in the remaining two subjects. The control group consisted of 12 patients undergoing bronchoscopy for routine diagnostic purposes (mean age 56, range 31-72 years; eight men; one Negro, two Asians and nine Europeans). Seven were found to have no pathological changes and in five lung cancer was diagnosed.

Seven of the control group were smokers, but only one of the subjects with sarcoidosis smoked. None of the subjects in this study was receiving any drugs at the time of bronchoalveolar lavage.

\section{BRONCHOALVEOLAR LAVAGE}

Bronchoalveolar lavage was performed with $180 \mathrm{ml}$ prewarmed buffered saline, instilled into the medial segment of the middle lobe or right lower lobe. In the control subjects with carcinoma the unaffected lung was lavaged.

Lavage fluid was spun at $2000 \mathrm{rev} / \mathrm{min}$ for 10 minutes at room temperature; the cell pellet was then washed twice in RPMI 1640, and cells were counted with a haemocytometer. Differential cell counts were performed on two cytocentrifuge preparations from each lavage sample after they had been stained with May-Grünwald-Giemsa 200 cells were counted on each slide.

\section{LYMPHOCYTE TRANSFORMATION}

Peripheral blood was diluted 1:1 with buffered salt solution (BSS), layered on to ficoll-hypaque gradients, and centrifuged for 35 minutes at $400 \mathrm{~g}$ at room temperature. The total mononuclear cells were recovered from the interface, washed twice in BSS, and resuspended in RPMI 1640 containing 5\% fetal calf serum. Two $\mathrm{ml}$ of $2 \times 10^{6}$ cells $/ \mathrm{ml}$ of either lavage fluid or peripheral blood mononuclear cells in RPMI 1640 with $5 \%$ fetal calf serum were dispensed into 24 well plates (Costar Ltd, UK) and incubated in $5 \%$ carbon dioxide at $37^{\circ} \mathrm{C}$. After one hour the nonadherent cells were removed by gentle suction with a Pasteur pipette and the adherent cells washed twice with RPMI 1640 and $2 \%$ fetal calf serum. Then $200 \mu \mathrm{l}$ of $2 \times 10^{6} / \mathrm{ml} \mathrm{non-adherent} \mathrm{cells} \mathrm{were} \mathrm{plated} \mathrm{into} \mathrm{flat}$ bottomed microtitre plates. A suboptimal (optimal dose $=20 \mu \mathrm{g} / \mathrm{ml}$ ) dose of concanavalin A $(2 \mu \mathrm{g} / \mathrm{ml}: 20 \mu \mathrm{l}$ of $20 \mu \mathrm{g} / \mathrm{ml}$ solution) was added to three wells, with another three wells acting as control. The plates were then incubated for three days in $5 \%$ carbon dioxide in air at $37^{\circ} \mathrm{C}$. Eighteen hours before the termination of this culture period $0.4 \mu \mathrm{Ci}$ of tritiated thymidine was added to each well. Cells were harvested on to glass fibre discs with a Titertek harvester. The discs were then dried and incorporation of tritiated thymidine into cells was determined by liquid scintillation counting using a Tri-Carb 4000 series counter (Packard Instruments Co Inc, USA).

\section{GENERATION OF INTERLEUKIN-1 AND} INTER LEUK IN-2

One ml RPMI 1640 containing 5\% fetal calf serum was added to the costar plate containing the adherent cells. These adherent cells were then stimulated with $5 \mu \mathrm{g} / \mathrm{ml} \quad(100 \mu \mathrm{l}$ of a $50 \mu \mathrm{g} / \mathrm{ml}$ solution) lipopolysaccharide to generate IL-1. A second well remained lipopolysaccharide free and acted as a control. The plates were incubated for 24 hours in an atmosphere of $5 \%$ carbon dioxide in air at $37^{\circ} \mathrm{C}$ and the supernatants were collected, centrifuged, and dialysed against $100 \mathrm{ml}$ RPMI 1640 , which was changed five times during 48 hours. The dialysates were stored at $-20^{\circ} \mathrm{C}$ until they were assayed.

We stimulated $2 \times 10^{6}$ non-adherent cells $/ \mathrm{ml}$ from lavage fluid or peripheral blood with $10 \mu \mathrm{g} / \mathrm{ml}$ concanavalin A Sigma UK Ltd $(100 \mu \mathrm{l}$ of a $100 \mu \mathrm{g} / \mathrm{ml}$ solution) for 24 hours at $37^{\circ} \mathrm{C}$ in $5 \%$ carbon dioxide in air. After this time concanavalin $\mathrm{A}$ was added to control cultures, after which the mitogen was 
absorbed out of all cultures with Sephadex 100 beads. The samples were then stored at $-20^{\circ} \mathrm{C}$ until they were assayed.

\section{Assays for interleukin-1 and interleukin-2 activity}

Samples of $100 \mu$ l containing $4 \times 10^{6}$ cells $/ \mathrm{ml}$ adherent cell depleted mouse thymocytes in RPMI $+5 \%$ fetal calf serum were plated into flat bottomed microtitre plates. Fifty millilitres of IL-1 containing control supernatant or RPMI was added and then half of the wells were stimulated with phytohaemagglutinin at a final concentration of 0.01 mitogenic units $/ \mathrm{ml}$. The plates were then incubated and harvested under the same conditions as for lymphocyte transformation

Phytohaemagglutinin stimulated cell lines from peripheral blood were used as the target, the method of Paganelli et al being used. ${ }^{12}$ These cells are dependent on their continued growth. A standard IL2 preparation was replaced with the test supernatant for $\mathbf{4 8}$ hours, tritiated thymidine being added for the final 18 hours of culture.

\section{CALCULATION OF RESULTS}

Results are expressed as counts per minute $(\mathrm{cpm}) \times$ $10^{3}$ incorporation of tritiated thymidine. Where appropriate, a stimulation index was calculated by dividing the $\mathrm{cpm} \times 10^{3}$ of the mitogen stimulated cultures by the unstimulated culture cpm. Statistical analysis was carried out with the unpaired or paired Student's $t$ test.

\section{Results}

\section{LAVAGE FLUID CELL COUNTS}

There was an increase in the total number of cells recovered from patients with both active and inactive sarcoidosis (table). This was due to a combination of increased fluid return and greater numbers of lymphocytes from patients with sarcoidosis than from the control group. This difference was greatest in the active group, where there was a slight decrease in

Recovery of total cells from bronchoalveolar lavage fluid and the differential cell count in control subjects and patients with sarcoidosis (means with standard errors in parentheses)

\begin{tabular}{lccc}
\hline & Controls & $\begin{array}{l}\text { Inactive } \\
\text { sarcoidosis }\end{array}$ & $\begin{array}{l}\text { Active } \\
\text { sarcoidosis }\end{array}$ \\
& & & \\
\hline Number of subjects & 12 & 5 & 7 \\
\% fluid return & 27 & 35 & 33 \\
Total cell count $\left(\times 10^{6}\right)$ & 31 & 44 & 41 \\
Cells/ml $\left(\times 10^{6}\right)$ & $0 \cdot 3$ & $0 \cdot 35$ & $0 \cdot 34$ \\
$\%$ macrophages & $82+/-9$ & $78+/-8$ & $52+/-9$ \\
$\%$ lymphocytes & $8+/-3$ & $15+/-4$ & $43+/-8$ \\
$\%$ neutrophils & $10+/-6$ & $7+/-2$ & $5+/-3$ \\
\hline
\end{tabular}

recovery of macrophages but a greater increase of lymphocytes. Although a greater percentage of fluid was recovered from the patients with sarcoidosis than from the controls the observed increase in total cell recovery was not due only to this as the cell count per millilitre of returned fluid was also increased $(\mathrm{p}<0.05)$.

IN VITRO CONCANAVALIN A LYMPHOCYTE RESPONSE FROM PERIPHERAL BLOOD AND LAVAGE FLUID

The proliferative response to concanavalin A of lymphocytes recovered by bronchoalveolar lavage from both patients and controls was much less that of lymphocytes from the peripheral blood of controls (figure). The response of cells from peripheral blood to concanavalin A was lower in all patients with sarcoidosis than in controls $(p<0.005)$. This peripheral anergy was similar in patients with both active and inactive sarcoidosis.

In lavage fluid by contrast the patients with sarcoidosis showed a greater proliferative response than did the controls. Subjects with active disease showed a greater response than the inactive group $(\mathrm{p}<0.05)$. There was also spontaneous proliferation in the background unstimulated cultures of lavage lymphocytes from patients with active sarcoidosis $(p<0.05)$. In terms of the stimulation index the results are similar in the three groups: control $3 \cdot 3$, inactive sarcoidosis $3 \cdot 1$, and active sarcoidosis $2 \cdot 6$.

\section{INTERLEUKIN-2 AND INTERLEUKIN-1}

\section{PRODUCTION}

The mitogen induced production of IL-2 by peripheral blood lymphocytes was reduced in patients with sarcoidosis, this effect being greatest in the active group ( $<<0.01$ ). In fluid both spontaneous production and mitogen induced IL-2 production was increased, greater amounts being produced by the patients with active sarcoidosis than by either of the other two groups. (spontaneous: $p<0.005$; stimulated: $\mathrm{p}<0.01$ )

The in vitro peripheral blood anergy associated with sarcoidosis is reflected in the reduced IL-1 production, from blood monocytes from the group with sarcoidosis, which was less than $25 \%$ of that of the control level (inactive group: $p<0.01$; active group: $\mathrm{p}<0.005$ ). Production of IL-1 from lavage macrophages was similar in patients with sarcoidosis and in control patients.

\section{Discussion}

We have found that the peripheral blood anergy seen in sarcoidosis is reflected by a reduction in the concentrations of IL-1 and IL-2 produced by peripheral 
Lymphocyte transformation

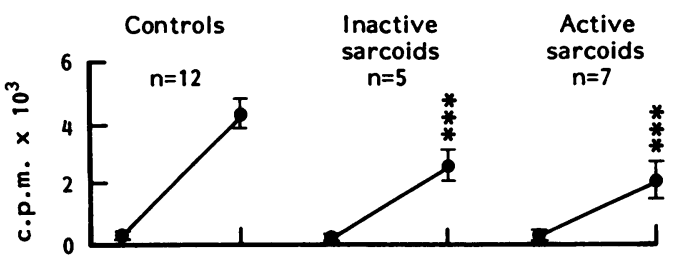

Interleukin-2 production

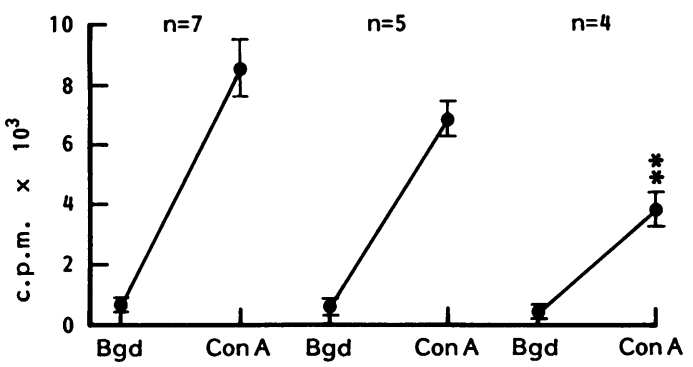

Interleukin-1 production

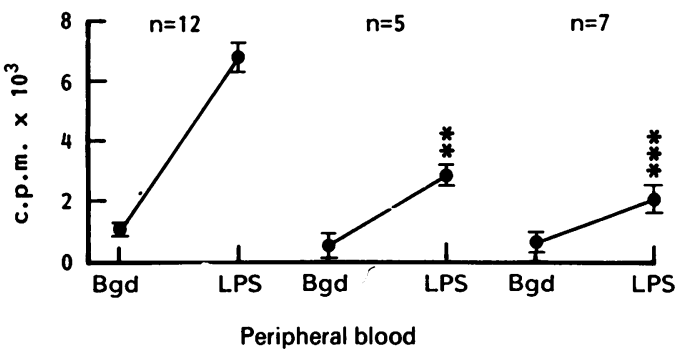

Lymphocyte transformation

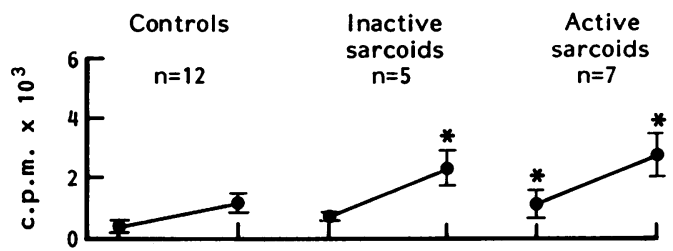

Interleukin-2 production

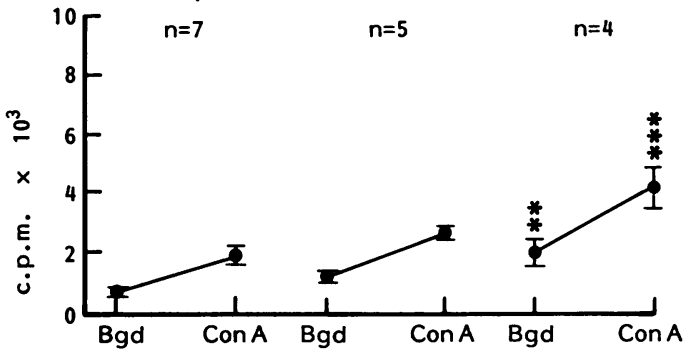

Interleukin-1 production

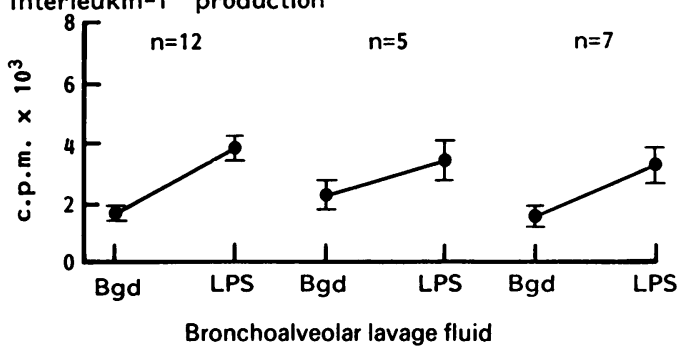

$T$ cell function, as measured by lymphocyte transformation, interleukin-2 production, and production of the monokine interleukin-1, measured in cells recovered from peripheral blood and bronchoalveolar lavage fluid. Bgd-background; LPS-lipopolysaccharide; Con A-concanavalin A; cpm-counts per minute. ${ }^{*} \_p<0.05$; $^{* *} \_p<0.01$; ${ }^{* *} \_p<0.001$.

blood mononuclear cells. In the lung, however, the increased proliferation of bronchoalveolar lavage fluid lymphocytes observed in both unstimulated and stimulated cultures in patients with active sarcoidosis is probably due to increased production of IL-2 and appears to be independent of IL-1 as no increase in the production of this monokine was observed in cultures of lavage fluid cells. Possibly these observed differences may be due to the smoking habits of the control group (all patients with sarcoidosis were nonsmokers). We found no difference, however, between the smoking and non-smoking controls in any of the indices measured in this study.

The observed IL-1 concentrations in lavage cell cultures differ from those reported by Hunninghake, ${ }^{13}$ who found increased IL-1 secretion by alveolar macrophages from patients with active sarcoidosis. This may reflect a difference in methods as he used a four hour culture period. Although our in vitro results differ this does not preclude a role for IL-1 in the activation of $T$ cells in vivo. The lavage macrophage may have already released IL-1 within the lung. The difference between our results and those of Hunninghake may reflect this because an enhanced IL-1 secretion during a four hour culture might be due to release of IL-1 synthesised by the cells when still within the lung, although no enhancing activity could be detected in lavage fluid. ${ }^{9}$ Our results obtained from 24 hour cultures are a measure of the capacity of these cells to synthesise IL-1.

The observed increased spontaneous proliferation of lymphocytes appears to occur in a subpopulation of lung lymphocytes in the group with active sarcoidosis. This was suggested by the fact that concanavalin A caused increased proliferation in all groups, while with the stimulation index, as measured by mitogen induced proliferation divided by spontaneous proliferation of resting lymphocytes, was similar in both 
groups of patients with sarcoidosis and the controls. The mitogen induces proliferation of resting lymphocytes only and therefore, even in active sarcoidosis, not all the cells have been activated in vivo.

We have previously shown that the peripheral blood anergy is due to activated cells of the monocyte-macrophage series, which not only have a reduced capacity for IL-1 production but also release increased amounts of prostaglandin $\mathrm{E}_{2}{ }^{3}$ The peripheral blood compartment has also been shown to contain increased proportions of lymphocytes bearing the suppressor phenotype and decreased numbers of T lymphocytes of the helper phenotype. ${ }^{47}$

In the lung, however, at the site of granuloma formation there is an increase of $\mathrm{T}$ lymphocytes, mainly with the helper cell phenotype. ${ }^{7}$ The question of the origin of these cells arises; do they migrate to the site of presumed immunological insult, thus causing the observed peripheral cell picture by a depletion phenomenon, or is there a local proliferation of helper $\mathrm{T}$ cells at the site of granuloma formation after the migration of a subpopulation of activated lymphocytes?

Although we found some spontaneous lymphocyte proliferation in the lavage cells from patients with active sarcoidosis we have also found that mitogen could enhance both proliferation, as measured by tritiated thymidine incorporation, and IL-2 production. This shows that many of the lymphocytes have not been activated in vivo but retain the capacity to be activated when stimulated by an appropriate signal. Possibly therefore they have migrated to the lung, perhaps under the control of a chemotactic factor. ${ }^{14}$ Other work has suggested that most of the lymphocytes found in lavage fluid from patients with sarcoidosis have arisen as a result of spontaneous local proliferation $^{9}$ and that this is the source of the increased numbers of $T$ lymphocytes of the helper phenotype. One group have claimed, however, that the increased number of lymphocytes is due to an increase in cells bearing the suppressor phenotype. ${ }^{14}$ An explanation for the different findings on phenotype may be that lavage lymphocytes might express both helper and suppressor markers, as recently shown by the studies of Davidson et al ${ }^{15}$ for cells from the lavage fluid of control subjects. The source and function of these $\mathrm{T} 4+/ \mathrm{T} 8+$ lymphocytes remains to be elucidated; possibly at different stages of the disease there is a fluctuation in this ratio.

Our results show that so far as the lung is concerned sarcoidosis is not a disease characterised by cellular immunodeficiency, as has been suggested by earlier work using peripheral blood. ${ }^{12}$ Sarcoidosis should be seen as a disorder in which compartmentalisation of the cells of the immune system appears to occur. The stimulus for the proposed cellu- lar migration into granulomas is not known, although $T$ cell derived chemotactic factors have been shown to be produced by lung cells. ${ }^{11}$ These factors could cause traffic of cells from the peripheral blood to the site of granuloma formation, leading to peripheral lymphopenia. The anergy observed in the peripheral compartment could be explained by a combination of this lymphopenia and the effect of chemotactic factors on monocytes that become activated. This leads to increased prostaglandin production and reduced capacity to produce IL-1, thus contributing to the peripheral anergy. What stimulates or controls the observed local cellular proliferation remains unclear.

Our results show that patients with sarcoidosis are not immunologically compromised because there is an activated competent cellular immune response at the site of disease activity, which might be the site of antigen challenge.

We would like to thank Miss MC Tomlinson for help with typing. KCF was supported by the Sir Jules Thorn Research Trust.

\section{References}

1 Siltzbach L. Sarcoidosis. In: Samter M, ed. Immunological diseases. Boston, Massachusetts: Little, Brown and Co, 1971:581-603.

2 Horsmanheimo M. Correlation of tuberculin-induced lymphocyte transformation with skin test reactivity and with clinical manifestations of sarcoidosis. Cell Immunol 1974;10:329-37.

3 Hudspith BN, Brostoff J, McNicol MW, Johnson N McI. Anergy in sarcoidosis: the role of interleukin-1 and prostaglandins in the depressed in vitro lymphocyte response. Clin Exp Immunol 1984;57:324-30.

4 Johnson N McI, Brostoff J, Hudspith BN, Boot JR, McNicol MW. T cells in sarcoidosis: $E$ rosetting monocytes suppress lymphocyte transformation. Clin Exp Immunol 1981;43:491-6.

5 Goodwin JS, De Horatius R, Israel H, Peake GT, Messner RP. Suppressor cell function in sarcoidosis. Ann Intern Med 1979;90:169-73.

6 Hunninghake GW, Fulmer JD, Young RC, Gadek JE, Crystal RG. Localisation of the immune response in sarcoidosis. Am Rev Respir Dis 1979;120:49-57.

7 Hunninghake GW, Crystal RG. Pulmonary sarcoidosis: a disorder mediated by excess helper T-lymphocyte activity at sites of disease activity. $N$ Engl J Med 1981;305:429-34.

8 Keogh BA, Hunninghake GW, Line RR, Crystal RG. The alveolitis of pulmonary sarcoidosis. Am Rev Respir Dis 1983;128:256-65.

9 Pinkston P, Bitterman PB, Crystal RG. Spontaneous release of interleukin-2 by lung T-lymphocytes in active pulmonary sarcoidosis. $N$ Engl J Med 1983;308:793-800.

10 Hunninghake GW, Broska P, Haber R, Keogh BA, 
Line BR, Crystal RG. Correlation of lung T-cell and macrophage function with disease activity in pulmonary sarcoidosis [abstract]. Clin Res 1981; 49:550.

11 Keogh BA, Hunninghake GW, Line BR, Crystal RG. The alveolitis of pulmonary sarcoidosis. Am Rev Respir Dis 1983;128:256-65.

12 Paganelli R, Aivili F, Beverley PCL, Levinsky RJ. Impaired production of interleukins in patients with cell-mediated immunodeficiency. Clin Exp Immunol 1983;51:338-44.
13 Hunninghake GW. Release of interleukin-1 by alveolar macrophages of patients with active pulmonary sarcoidosis. Am Rev Respir Dis 1984;129:569-72.

14 Hunninghake GW, Gadek JE, Young RC, Kawanami O, Farrans VJ, Crystal RG. Maintenance of granuloma formation in pulmonary sarcoidosis by lymphocytes within the lung. $N$ Engl $J$ Med 1980;302:594-8.

15 Greening AP, Nunn P, Dobson N, Rudolf M, Rees ADM. Pulmonary sarcoidosis: alteration in bronchoalveolar lymphocytes and $\mathrm{T}$ cell subsets. Thorax 1985;40:278-83. 